\title{
Research Paradigm: A Philosophy of Educational Research
}

\author{
Krishna Kumar Khatri
}

Lecturer, Department of English Education, Mahendra Ratna Multiple Campus, Tribhuvan University, Nepal

\begin{abstract}
This paper attempts to provide insights on research paradigm as the philosophical foundation for educational research. The main purpose of writing this paper is to provide basic idea and knowledge about research paradigm to the prospective researcher with a claim as it is a philosophy of educational research. Different books and journal articles were consulted, reviewed and discussed to prepare this write up. After accumulating the idea and insights on research paradigms, the paper begins with the overview of research in terms of basic features. Then, it introduces about the research paradigms as the research philosophy and followed by the major components of research paradigms viz. ontology, epistemology, methodology and axiology. The key components of research paradigms are defined and discussed in terms of their basic premises in relation to the educational research contexts. Moreover, the paper also presents a brief discussion on the implications of research paradigms in educational research.
\end{abstract}

Keywords-Axiology, epistemology, methodology, ontology, research paradigm, research implications.

\section{INTRODUCTION}

Research is an organized and systematic approach of inquiry on specific phenomenon. It refers to the process through which the researcher accomplishes answers to research questions. The term research is defined in various ways by different scholars in the field. Creswell (2012), defines research as "a process of steps used to collect and analysis information to increase our understanding of a topic or issue (p.3)". Here, Creswell regards research as a process followed in understanding of certain issue through the collection and analysis of the data. Moreover, Denzin, and Lincoln (2005), state research as "an organized scholarly activity that is deeply connected to power ( $\mathrm{p}$, 87)". This definition implies that research can be understood as a systematic scholarly process of acquiring knowledge, power and position in which it takes place. Similarly, Cohen, Manion and Morrison (2008) write "Research is the systematic and scholarly application of the principles of a science of behavior to the problem of people within their social context (P. 48). From this definition, it can be inferred that research follows scientific procedures to study the phenomena and problems in a social context where problem exist. It allows interaction between the researchers and social behaviors and ongoing social activities. In course of research, researcher has to supply philosophical and theoretical foundation of his/her research work. Moreover, the researcher has to create his /her position to view the world and phenomena that guides him/her towards certain destinations. Therefore, this paper attempts to define and discuss research paradigm in terms of its four philosophical perspectives. Moreover, the paper also presents some implications of research paradigm in the educational research. Regarding the methodology, the paper has been prepared consulting secondary sources of data in which different books, journal articles and research reports were reviewed and ideas and statements have been extracted to discuss the ideas throughout the paper.

\section{RESEARCH PARADIGM: A PHILOSOPHICAL FOUNDATION OF RESEARCH}

Simply, research paradigm refers to the theoretical or philosophical ground for the research work. It is viewed as a research philosophy. American philosopher Thomas Kuhn (1962) first used the word paradigm in the field of research to mean a philosophical way of thinking. In educational research, the term paradigm is used to describe a researcher's 'worldview' (Mackenzie \& Knipe, 2006). This worldview is the perspective, or thinking, or school of thought, or set of shared beliefs, that informs the meaning or interpretation of research data. In the same regard, Willis (2007) defines research paradigm as "a comprehensive belief system, worldview or framework that guides research and practice in a field (p.8)". Thus, it is the 
researcher's thoughts and beliefs about any issues explored would subsequently guide their actions. It directs the researcher in the overall process of investigation including selection of research problem, setting research questions, determining the nature and types of reality, knowledge, methodology and value of the research work.

In this vein, Lather (1986) mentions that a research paradigm inherently reflects the researcher's beliefs about the world that s/he lives in and wants to live in. It constitutes the abstract beliefs and principles that shape how a researcher sees the world, and how s/he interprets and acts within that world. Moreover, Hughes, (2010) says "paradigm is perceived as a way of seeing the world that frames a research topic and influences the way that researchers think about the topic (p. 35)". Fraser and Robinson (2004) further argue that a paradigm is "a set of beliefs about the way in which particular problems exist and a set of agreements on how such problems can be investigated". Likewise, Guba and Lincoln (1994) who are leaders in the field define a paradigm as a basic set of beliefs or worldview that guides research action or an investigation". Similarly, Denzin and Lincoln (2000), state that paradigm as human a construction, which deals with first principles or ultimate indicating where the researcher is coming from so as to construct meaning embedded in data. From the above discussions, we can say that research paradigm constitutes researcher's worldview, abstract beliefs and principles that shape how he/she sees the world, and how s/he interprets and acts within that world. It is the lens through which a researcher looks at the research topic and examines the methodological aspects of their research work being based on certain philosophical foundation. In a similar vein, Kivunja and Kuyini, 2017) mention that paradigms are thus important because they provide beliefs and dictates, which, for scholars in a particular discipline, influence what should be studied, how it should be studied, and how the results of the study should be interpreted. The paradigm defines a researcher's philosophical orientation and exerts significant implications for every decision made in the research process, including nature of reality, types and sources of knowledge and choice of methodology and methods. Thus, all researches are required to be based on some underlying philosophical assumptions about what constitutes 'valid' research. In order to conduct and evaluate any research, it is therefore important to know what these assumptions are. So, the following section will briefly discuss the major components of research paradigm which also constitute philosophical assumptions of research paradigms.

\section{COMPONENTS OF RESEARCH PARADIGMS}

As literature suggests, research paradigm is a basic and comprehensive belief system to view the research phenomena. It is the researcher's worldview perspective, or thinking, or school of thought, or set of shared beliefs that inform about the meaning or interpretation of research data. In course of research, it is important for the researcher to be aware and informed about his/her position on seeing and observing the world and its phenomena. It means he/she needs to have clear philosophical perspectives about how the reality or truth is viewed, how the knowledge is gained by what methods and methodology and how values are addressed in the research being carried out based on a particular research paradigm. Thus, such perspectives and assumptions through which reality, knowledge, methodological approaches and values are defined under each paradigm are simply known as components of research paradigm. According to Lincoln and Guba (1985), a paradigm comprises four elements, namely, epistemology, ontology, methodology and axiology. The perspectives of research paradigm pronounce Ontology- as the nature of reality, Epistemology- as the nature of knowledge and the relationship between the knower and that which would be known, Methodology- as the appropriate approach to systematic inquiry and Axiology- as the nature of ethics (Mertens, 2010). To be specific, ontology, epistemology, methodology and axiology are the components of research paradigm. Thus, it is important to have a firm understanding of these elements because they comprise the basic assumptions, beliefs, norms and values that each paradigm holds. In what follows, the next section presents a brief description of four perspectives/components of research paradigm.

\section{Ontology}

Ontology deals with the philosophical assumptions about the nature of reality or existence. It is simply called theory of reality. As Scotland (2012) says that ontology is a branch of philosophy concerned with the assumptions we make in order to believe that something makes sense or is real, or the very nature or essence of the social phenomenon we are investigating. Similarly, in Krauss's, (2005) words, "ontology involves the philosophy of reality (p. 758)". Moreover, Scott and Morrison (2005) states that ontology deals with the level of reality present in certain events and objects, but more importantly with the systems which shape our perceptions of these events and objects (p. 170)". Thus, ontology is the philosophical standpoint about the nature of existence or reality, of being or becoming, as well as the basic categories of things that 
exist and their relations. It examines underlying belief system of the researcher, about the nature of being and existence. It helps to conceptualize the form and nature of reality and what you believe can be known about that reality. In course of research, ontology makes the researcher to seek the answer to the questions like: Is there reality out there in the social world or is it a construction, created by one's own mind? What is the nature of reality? In other words, Is reality of an objective nature, or the result of individual cognition? What is the nature of the situation being studied? Therefore, ontology is essential to a researcher because it helps to provide an understanding of the things that constitute the world as it is known (Scott \& Usher, 2004). It also helps the researcher orientate his/her thinking about epistemological and methodological beliefs in relation to the research problem so as to contribute to its solution.

\section{Epistemology}

Epistemology is another component of research paradigm dealing with how knowledge is gained from different sources. It is simply known as theory and philosophy of knowledge. Trochim (2000) contends, "epistemology is the philosophy of knowledge or how we come to know p. 758)". Similarly, Blaikie (1993) describes epistemology as "the theory or science of the method or grounds of knowledge' expanding this into a set of claims or assumptions about the ways in which it is possible to gain knowledge of reality" (as cited in Flowers, 2009, p 2). In research, epistemology is used to describe how we come to know something; how we know the truth or reality. Regarding epistemology, Cooksey and McDonald (2011) state that what counts as knowledge within the world. Moreover, it is concerned with the very bases of knowledge - its nature, and forms and how it can be acquired, and how it can be communicated to other human beings. It focuses on the nature of human knowledge and comprehension that you, as the researcher or knower, can possibly acquire so as to be able to extend, broaden and deepen understanding in your field of research. While stating the epistemological assumptions in the research, the researcher seeks to answer the questions such as: What is the nature of knowledge and the relationship between the knower and the would-be known? Guba \& Lincoln (1994), Is knowledge something which can be acquired on the one hand, or, is it something which has to be personally experienced? What is the relationship between me, as the inquirer, and what is known? These questions are important because they help the researchers to position themselves in the research context so that they can discover what else is new, given what is known (Kivunja and Kuyini, 2017). Along with these very questions, it is also important to know the answer of the questions: what counts as Knowledge?

To articulate the answer to these questions, it is essential to be informed about the sources of knowledge as suggested by (Slavin, 1984), intuitive knowledge- based on beliefs, faith, and intuition; authoritative knowledgegathered from people in the know, books, leaders in organizations; logical knowledge- the reason as the surest path to knowing the truth; and empirical knowledgederived from sense experiences, and demonstrable, objective facts. Thus epistemology is a philosophical perspective about the nature and sources of knowledge gained during the research. Epistemology is important because, it helps to establish the faith put in data. It affects how the researcher will go about uncovering knowledge in the social context that he/she will investigate. It provides guidelines to researchers to define the scope of entire research.

\section{Methodology}

Methodology is an important component of research paradigm. It deals with the how aspects of inquiry process. Keeves (1997) states that methodology is the broad term used to refer to the research design, methods, approaches and procedures used in an investigation that is well-planned to find out something. From this, it is inferred that methodological considerations in a paradigm simply include participants, instruments used in data gathering, and measures for data analysis through which knowledge is gained about the research problem. The methodology articulates the logic and flow of the systematic processes followed in conducting a research project, so as to gain knowledge about a research problem. It includes assumptions made, limitations encountered and how they were mitigated or minimized. It focuses on how we come to know the world or gain knowledge about part of it (Moreno, 1947). Moreover, methodology is concerned with the question like: How shall I go about obtaining the desired data, knowledge and understandings that will enable me to answer my research question and thus make a contribution to knowledge? In a similar vein, Guba, \& Lincoln (1994) mention that the methodological question asks "how can the inquirer (would be knower) go about finding out whatever he or she believes can be known? (p. 108)". Form this; it is clear that methodological questions guide the researcher to the process of knowing through which the research questions are answered. Therefore, the researcher should have clear understanding of the methodological assumptions to be employed in course of his/her own research. 


\section{Axiology}

Axiology is another component of research paradigm dealing with ethical issues that need to be considered during research work. It considers the philosophical approach to making decisions of value or the right decisions (Finnis, 1980). Therefore, it is called theory of value. It involves defining, evaluating and understanding concepts of right and wrong behaviour relating to the research. It considers what value we shall attribute to the different aspects of our research, the participants, the data and the audience to which we shall report the results of our research. Axiology addresses the questions such as: What is the nature of ethics or ethical behaviour? What values will you live by or be guided by as you conduct your research? What ought to be done to respect all participants' rights? What are the moral issues and characteristics that need to be considered? Which cultural, intercultural and moral issues arise and how will I address them? How shall I secure the goodwill of participants? How shall I conduct the research in a socially just, respectful and peaceful manner? How shall I avoid or minimize risk or harm, whether it be physical, psychological, legal, social, economic or other? (ARC, 2015, as cited in Kivunja and Kuyini, 2017).

Specifically, the theory of value is concerned with two aspects: ethics and aesthetics. Ethics is the philosophical approach to making the right decision. It also involves defining, evaluating and understanding concepts of right and wrong behavior. In this side, the researcher needs to consider typical ethical questions such as: what is good/bad? What is right/wrong? What is the foundation of moral principles? What is justice? Aesthetics deals with the study of the nature and value of works and the aesthetic experience. The typical aesthetic questions include: why are works of research considered to be valuable? What is beauty? These questions might be different in different research disciplines and research paradigms.

\section{IMPLICATIONS OF RESEARCH PARADIGM IN EDUCATIONAL RESEARCH}

As stated and discussed above, research paradigm is a philosophical standpoint of the researcher from which research phenomena are observed and analyzed. It is the comprehensive belief system and philosophical worldview that guide the process and actions of the whole research activity. More specifically, research paradigm is a philosophical base of research dealing with the nature of reality, whether it is external or internal (i.e., ontology); the nature, type and sources of knowledge generation (i.e., epistemology); a disciplined approach to generate that knowledge (i.e., methodology); the ethical issues that need to be considered in research (i.e. axiology). Moreover, the research paradigm guides the researcher to frame and proceed his/her research activity and to derive certain meaning of the researched phenomena. In this regard, Joubish et al. (2011) opined that paradigm guides a whole framework of beliefs, values and methods within which research takes place. The researcher should create a clear position regarding the reality that his/her research believes , the nature and sources of knowledge that the research derives, the methods he/she employs to gain meaning of the researched phenomenon and he/she needs to be equally sensitive to the values of the research activity. For all these concerns, researcher needs to be based on certain research paradigm and its basic philosophical perspectives. In addition, the research paradigm provides philosophical foundation for the researcher to determine the basic philosophical dimensions: such as ontology, epistemology, methodology and axiology of his/her research work.

Ontology is one of the important philosophical dimensions of research paradigm. It refers to the nature of reality and what human beings can know about it (Guba \& Lincoln, 1994). In course of research, the researcher should clearly define about the ontological position of his/her research. The researcher needs to mention about how his/her research states about the nature of reality that is derived from the researched phenomena. He/she should have clear position whether there is subjective reality or objective reality as derived by the research work. Regarding this, researcher needs to have knowledge of a specific research paradigm. The research paradigm provides clear framework and guidelines to the researcher about the worldview of reality. In the same line, the nature of reality is determined by the nature of phenomena to be researched. If the researched phenomenon is about the relationship between different variables and testing of hypothesis, it leads towards the objective reality whereas if the phenomena to be researched are about the human experiences and social cultural processes, the researcher's ontological beliefs will be multiple realities. Therefore, researcher should have explicit understanding of research paradigm during the research.

Epistemology is another important component of research paradigm that researcher needs to consider in course of research. Epistemological assumptions refer to the nature of the relationship between the knower and what can be known (Guba \& Lincoln, 1994). As research is a process of generating knowledge following certain procedures, the researcher can be based on particular framework and research paradigm. Moreover, the 
researcher needs to be aware of epistemological questions such as: What is the nature of knowledge and the relationship between the knower and the would-be known? Guba \& Lincoln (1994). To answer these questions, the researcher can consult particular type of research paradigm from which he/she can direct the research process to generate knowledge. Thus, research paradigm provides clear framework to the researcher for determining the type, nature and sources of knowledge that his/her research generates after the completion. So, it is important for the researcher to have concrete understanding of a particular research paradigm before starting research journey. Similarly, the researcher needs to be clear about the notion that epistemological standpoint varies according to research paradigm from which he/she determines the epistemological assumptions of his/her research.

In the same way, methodological consideration is another important component of research paradigm. In course of research, the researcher should clearly define how he/she is going to find out the meaning of the phenomenon to be researched. Guba \& Lincoln (1994) state that methodological assumptions refer to how the researcher can go about discovering the social experience, how it is created, and how it gives meaning to human life. Thus, methodology is the theory and a disciplined approach that informs about how researchers gain knowledge in research contexts. In the academic research, the researcher has to specify the subjects, tools, measures and techniques to be employed in his/her research work. In order to get firm understanding about all methodological considerations, the researchers can gain insight form research paradigm that clearly guides about the how aspects of the research.

Similarly, the research paradigm is equally contributory to the researcher to define and determine the value system that his/her research addresses. In the research, the researcher needs consider about the ethical issues. The researcher should be clear whether his research is value free of value laden. For this issue, research paradigm provides explicit framework and guidelines to the researcher. So research paradigm is important for the researcher. Nonetheless, different paradigms have different assumptions about the value system being either value free or value laden. Axiological assumptions of research paradigm help the researcher to think about the space of researched subjects, contexts and him in the entire research works. In addition, this component is also important for the researcher to determine what things and activities are good and acceptable and what are not. The researcher becomes aware of the ethical issues to be followed by him own side and from the side of participants. Moreover, axiology makes the researcher aware of the respect, space and justice of the participants in the entire research. Thus, the insight of the research paradigm is essential for the researcher to address the ethical and aesthetic issues in the research work.

\section{CONCLUSION}

Research paradigm is simply known as philosophical foundation or framework of a research work. It is also termed as comprehensive belief system and world view that guides the researcher to frame his/her research process in certain pattern. In other words, it is also taken as the philosophical positions of the researcher in the research in which he/she claims and justifies how he/she views the reality, what his/ her assumptions about knowledge, methodology and value. To make clear, research paradigm explicitly states the researcher's positions on ontology, epistemology, methodology and axiology of his/her research work. This philosophical positioning of the researcher becomes a philosophical dimension of his/her research. The philosophical base of the research guides the researcher to precede the entire process and derive the meaning form the researched phenomenon. Therefore, the knowledge of research is essential for the researcher to create his/her own research philosophy.

\section{REFERENCES}

[1] Carr, W. L., \& Kemmis, S. (1986). Becoming critical: Education, knowledge and action research. London: Falmer.

[2] Cohen, L. , Manion, L. \& Morrison, K. (2007). Research methods in education. London: Routledge

[3] Cooksey, R. \& McDonald, G. (2011). Surviving and thriving in postgraduate research, Prahran:VIC, Tilde.

[4] Creswell, J. W. (2012). Qualitative inquiry \& research design: Choosing among five approaches (2nd ed.). Thousand Oaks, CA: Sage Publications.

[5] Denzin, N. K., \& Lincoln, Y. S. (2005). SAGE Handbook of qualitative research (3rd ed.). Thousand Oaks, CA: Sage Publications.

[6] Denzin, N. K. \& Lincoln, Y.S. (2000). Handbook of qualitative research. Sage, London: Sage

[7] Fadhel, K. (2002). Positivist and hermeneutic paradigm: A critical evaluation under their structure of scientific Practice, The Sosland Journal, 21-28.

[8] Finnis, J. (1980). Natural law and natural rights. Oxford: Clarendon Press.

[9] Flowers, P. (2009). Research Philosophies - Importance and Relevance. Online published paper. Cranfield School of Management.

[10] Fraser, S. \& Robinson, C. (2004). Paradigms and philosophy. In S. Fraser, V. Lewis, S. Ding, M. Kellett and 
C. Robinson (Eds.), Doing research with children and young people. London: Sage.

[11] Guba, E. (1990). The paradigm dialog. Sage, California: Sage

[12] Guba, E. G. \& Lincoln. Y.S. (1989). What is this constructivist paradigm anyway? In fourth generation evaluation. London: Sage Publications, 79-90.

[13] Guba, E. G. and Lincoln, Y. S. (1994) Competing paradigms in qualitative research. In N.K Denzin,. \& Y. S. Lincoln, (1994, eds. ) Handbook of qualitative research. (pp. 105117). London: Sage.

[14] Hughes, P. (2010). Paradigms, methods and knowledge. In G. Mac Naughton, S. Rolfe and I. Siraj-Blatchford (Eds.), Doing early childhood research. Maidenhead: Open University Press

[15] Joubish, M. F., Khurram, M.A.,Ahmed, A., Fatima, S. T. and Haider,K. (2011). Paradigm and Characteristics of a Good Qualitative Research. World Applied Sciences Journal, 12(11), 2082-2087. IDOSI Publication.

[16] Keeves, J. P. (1997). Educational research methodology and measurement. Cambridge: Cambridge University Press.

[17] Kincheloe, J. L., \& McLaren, P. (2000). Rethinking critical theory and qualitative research. In N. K. Denzin \& Y. S. Lincoln (Eds.), Handbook of qualitative research 2 nd ed.,( pp. 279-313). Thousand Oaks, CA: Sage.

[18] Kivunja, C. \& Kuyini, A. B. (2017). Understanding and applying research paradigms in educational contexts. International Journal of Higher Education, 6 ( 5), 26-41.

[19] Krauss, S. E. (2005). Research paradigms and meaning making: A primer. The Qualitative Report, 10(4), 758-770. Retrieved [Insert date], from http://www.nova.edu/ssss/QR/QR10-4/krauss.pdf.

[20] Kuhn, T. S. (1962). The structure of scientific revolutions. (1st Edn). Chicago, IL: University of Chicago Press.

[21] Lather, P. (1986). Research as praxis. Harvard Educational Review, 56(3), 257-277.

[22] Lincoln, Y., \& Guba, E. (1985). Naturalistic inquiry. Thousand Oaks, CA: Sage.

[23] Mackenzie, N. \& Knipe, S. (2006). Research dilemmas: Paradigms, methods and methodology. Issues In Educational Research, 16, 1-15.

[24] Manen, M. V. (1990). Researching lived experience. London, ON: State University of New York Press.

[25] Martens, D. M. (2015). Research and evaluation in education and psychology. 4th Edn. Los Angeles: Sage.

[26] Mertens, D. M. (2010). Transformative Mixed Methods Research. Qualitative Inquiry 16(6), pp. 469-474. Retrieved from http://qix.sagepub.com.

[27] Moreno, J. (1947). Contribution of sociometry to research methodology in sociology. American Sociological Review, 12(6), $287-292$.

[28] Morgan, D. L. (2007). Paradigms lost and pragmatism regained: Methodological implications of combining. New Delhi: Sage Publications.

[29] Scotland, J. (2012). Exploring the philosophical underpinnings of research: Relating ontology and epistemology to the methodology and methods of the scientific, interpretive, and critical research paradigms. English Language Teaching, 5(9), 9-16. doi.org/10.5539/elt.v5n9p9.

[30] Scott, D. and Morrison, M. (2005). Key ideas in educational research. London: Continuum.

[31] Scott. D. \& Usher, R. (2004). Researching education: Data, methods, and theory in educational enquiry. New York: Continuum.

[32] Slavin, R. E. (1984). Research methods in education: A practical guide. Englewood Cliffs, NJ: Prentice-Hall.

[33] Trochim, W. M. (2000). The research methods knowledge base. Retrieved from http://www.socialresearchmethods.net/kb/

[34] Willis, J. W. (2007). Foundations of qualitative research: Interpretive and critical approaches. Thousand Oaks, CA: Sage Publications. 